\title{
EFEITO DA DENSIDADE DE PLANTIO NA PRODUÇÃO ORGÂNICA DE MINIMILHO NO SEMIÁRIDO POTIGUAR
}

\author{
B. B. ARAÚJO JUNIOR ${ }^{1}$, R. S. CASTRO ${ }^{2}$, M. M. DANTAS ${ }^{3}$ \\ 1, 2, 3 Instituto Federal do Rio Grande do Norte (IFRN) - Campus Ipanguaçu \\ bernardo.bezerra@ifrn.edu.br
}

Submetido 21/12/2016 - Aceito 19/02/2018

DOI: $10.15628 /$ holos.2018.5484

\section{RESUMO}

O cultivo do milho para produção de minimilho destacase como uma opção de exploração dessa cultura, principalmente para pequenos produtores, sendo os tratos culturais semelhantes aos empregados nos cultivos tradicionais, exceto para a densidade de semeadura que pode ser até três vezes maior. Diante disso, foi desenvolvido um ensaio com o objetivo de avaliar o efeito do espaçamento e densidade de plantas sobre o rendimento de minimilho em sistema orgânico no semiárido potiguar. $O$ experimento foi conduzido na Horta experimental da Fazenda Escola do Instituto Federal do Rio Grande do Norte, Campus Ipanguaçu, entre os meses de janeiro a março de 2012, utilizando delineamento experimental em blocos ao acaso com quatro repetições e seis tratamentos que consistiram dos espaçamentos entre covas de 0,$4 ; 0,3 ; 0,2$ e 0,15 m, com duas plantas por cova, correspondendo as densidades de 5,$0 ; 7,0 ; 10,0$ e 13,0 plantas $\mathrm{m}^{-1}$, respectivamente, e dos espaçamentos de 0,2 e 0,15 m, com uma planta por cova $\left(5,0\right.$ e 7,0 plantas $\mathrm{m}^{-1}$, respectivamente). Foram avaliados o número e rendimento de espiguetas totais e comercializáveis, empalhadas e despalhadas. Foi observado efeito linear positivo para o aumento da densidade entre os tratamentos com duas plantas por cova, promovendo incrementos significativos para número e rendimento de espiguetas, sendo os maiores valores observados no tratamento com 13,0 plantas $\mathrm{m}^{-1}$.

PALAVRAS-CHAVE: Zea mays, Agricultura orgânica, Espaçamento entre covas, Produtividade.

\section{EFFECT OF PLANTING DENSITY ON THE ORGANIC PRODUCTION OF BABY CORN IN THE POTIGUAR SEMIARID}

\section{ABSTRACT}

The production of baby corn stands out as an option to exploit in the crop corn, mainly for small farmer, and the cultural techniques are similar to those used in traditional cultivation, except for the seeding density that can be up to three times higher. Based on this, an experiment was developed with the objective of evaluating the effect of plant spacing and density on baby corn production characteristics in the organic system in the semi-arid region. This study was conducted in the Experimental Crops Garden of the Federal Institute of Rio Grande do Norte, Ipanguaçu Campus, between January and March of 2012, using a randomized complete block design with Four replications and six treatments which consisted of pits spacings of $0.4 ; 0.3 ; 0.2$ and $0.15 \mathrm{~m}$ apart, with two plants per pit, corresponding to densities of $5.0 ; 7.0$; 10.0 and 13.0 plants $\mathrm{m}^{-1}$, respectively, and the pits spacings of 0.2 and $0.15 \mathrm{~m}$ apart, with one plant per pit, (5.0 and 7.0 plants $\mathrm{m}^{-1}$, respectively). Positive linear effect was observed for the increase in plant density between treatments with two plants per pit, promoting significant increases in number and yield of spikelets, with the highest values observed in the treatment with 13.0 plants $\mathrm{m}^{-1}$.

KEY-WORDS: Zea mays, Organic agriculture, Pits spacing apart, Productivity. 


\section{INTRODUÇÃO}

A cultura do milho (Zea mays L.) é uma das mais importantes para o Nordeste brasileiro devido a questões culturais e sua multiplicidade de uso, integrando a base alimentar de muitas famílias desta região. No estado do Rio Grande do Norte essa cultura é explorada nos 167 municípios, com destaque para as produções de espigas verdes e de grãos secos. A manutenção e a possível expansão da cultura do milho como atividade comercial passam necessariamente pela eficiência com que os produtores conduzem as suas lavouras e na forma que encontram de agregar valor ao seu produto (Araújo JR et al., 2012; Araújo Junior et al., 2015)

Uma opção para a exploração da cultura do milho seria a produção de minimilho, que consiste em espigas colhidas em dois ou três dias após a emergência do estilo-estigma (Silva et al., 2013). O Brasil apresenta um mercado promissor com o aumento da procura pelo minimilho e a produção brasileira é quase nula. Sendo assim, o minimilho tornou-se um produto atrativo também ao pequeno produtor, haja vista que os tratos culturais para produção deste são semelhantes aos empregados para produção do milho verde ou de grãos, havendo apenas uma diminuição no ciclo da cultura, sendo a colheita das espiguetas realizada de forma antecipada (Castro et al., 2013). O cultivo do minimilho irrigado surge como alternativa econômica para o semiárido, principalmente para a agricultura familiar, durante a estação seca do ano. Por ser de ciclo mais curto e apresentar a vantagem de ser colhido no início da fase reprodutiva há um menor consumo de água e energia, quando comparada a produção de milho verde (Melo et al., 2012).

O manejo da cultura do milho para a produção de minimilho pode diferenciar-se do cultivo para grãos principalmente quanto à densidade de semeadura, que pode ser pelo menos três vezes maior. A variação do número de plantas por área influencia as características comerciais do produto (Pereira Filho \& Cruz, 2002). Os autores destacam ainda que pelo fato da colheita ser toda processada manualmente, o espaçamento entre linhas não deve ser muito fechado, para não dificultar a movimentação dos trabalhadores.

Várias pesquisas com o minimilho foram desenvolvidas no Brasil nos últimos anos, sendo algumas realizadas no semiárido (Silva et al., 2006; Moreira et al., 2010; Castro et al., 2013; Silva et al., 2013). Porém, são raros os trabalhos visando a produção orgânica sob essa condição climática. Com base no exposto objetivou-se avaliar o efeito do espaçamento e da densidade de plantio do milho para produção de minimilho orgânico no semiárido potiguar.

\section{MATERIAIS E MÉTODOS}

O ensaio foi conduzido na Horta Experimental da Fazenda Escola do Instituto Federal de Educação, Ciência e Tecnologia do Rio Grande do Norte (IFRN - Campus Ipanguaçu) localizado no distrito de Base Física, a $4 \mathrm{~km}$ do município de Ipanguaçu-RN durante o período de janeiro a março de 2012. O clima da região, de acordo com a classificação de Koeppen, é do tipo BSwh', ou seja, quente e seco, com precipitação pluviométrica bastante irregular, com média anual de 550 $\mathrm{mm}$ e temperatura média anual de $26,2^{\circ} \mathrm{C}$ (Costa \& Silva, 2009).

O delineamento experimental foi em blocos casualizados com quatro repetições e seis tratamentos, totalizando vinte e quatro parcelas experimentais, sendo cada parcela composta por três fileiras de plantas espaçadas de 1,0 m entre si, com 4,0 $\mathrm{m}$ de comprimento, sendo a fileira central tida como área útil, e as covas das extremidades dessa fileira e as fileiras laterais 
tidas como bordadura. O espaçamento entre covas na fileira variou conforme os tratamentos, que tiveram uma ou duas plantas por cova. Para os tratamentos com duas plantas por cova foram utilizados os espaçamentos entre covas de 0,4 $\mathrm{m}$ (T1); 0,3 m (T2); 0,2 m (T3) e 0,15 m (T4), perfazendo as densidades 5,0; 7,0; 10,0 e 13 plantas por metro linear. Para os tratamentos com uma planta por cova foram testados os espaçamentos de 0,2 m (T5) e 0,15 m (T6), correspondendo as densidades 5,0 e 7,0 plantas por metro linear, respectivamente.

O solo da área é classificado como Neossolo Flúvico (Embrapa, 2006), e a sua fertilidade está descrita na Tabela 1.

Tabela 1. Análise química do solo da área experimental, da camada de 0 - $10 \mathrm{~cm}$. Ipanguaçu - RN, IFRN, 2012.

\begin{tabular}{|c|c|c|c|c|c|c|c|c|}
\hline $\mathrm{pH}$ & $\mathrm{P}$ (resina) & $\overline{\mathrm{K}^{+}}$ & $\mathrm{Na}^{+}$ & $\overline{\mathrm{Ca}^{+}}$ & ${\mathrm{Mg} 2^{+}}^{-}$ & SB & $t$ & MOS \\
\hline $\mathrm{CaCl}_{2}$ & $\mathrm{mg} \mathrm{dm}^{-3}$ & & $\overline{-\cdots}$ & ----m & $n^{-3}-\cdots$ & - & & $\%$ \\
\hline 7,0 & 43 & 3,6 & 91 & 68 & 29 & 100,6 & 118 & 1,1 \\
\hline
\end{tabular}

SB: soma de bases; t: CTC efetiva; MOS: matéria orgânica do solo

A área foi preparada com duas gradagens e foi feita adubação de plantio utilizando $20 \mathrm{t}$ ha ${ }^{-1}$ de esterco bovino curtido cuja resultado da análise se encontra na Tabela 2, distribuído e incorporado na linha de plantio. A partir dos 20 dias após a semeadura foram realizadas pulverizações semanais utilizando urina de vaca, como adubação de cobertura, na concentração de $1,0 \%$ via colo da planta, por quatro semanas.

Tabela 2. Análise química do esterco bovino (material seco) utilizado como adubo. Ipanguaçu - RN, IFRN, 2012.

\begin{tabular}{|c|c|c|c|c|c|c|c|}
\hline $\mathrm{pH}$ & C orgânico & $\mathrm{N}$ & $\mathrm{P}_{2} \mathrm{O}_{5}$ & $\mathrm{~K}_{2} \mathrm{O}$ & $\mathrm{Ca}^{2+}$ & $\mathrm{Mg}^{2+}$ & Relação C/N \\
\hline $\mathrm{H}_{2} \mathrm{O}$ & & - & ---- 9 & ----- &  & & \\
\hline 7,21 & 19,44 & 2,03 & 0,85 & 1,55 & 2,53 & 0,99 & 9,58 \\
\hline
\end{tabular}

A semeadura foi realizada utilizando a variedade Al Bandeirante, material de polinização aberta desenvolvida pela Coordenadoria de Assistência Técnica Integral (CATI), com quatro sementes por cova. Aos 15 dias após a semeadura, com base no desenvolvimento inicial das plantas, foi realizado desbaste deixando-se a quantidade de plantas por cova de acordo com o tratamento.

A partir dos 20 dias após a semeadura, foi realizado o manejo fitossanitário de forma preventiva da lagarta do cartucho (Spodoptera frugiperda) através de pulverizações semanais utilizando extrato de nim (Azadirachta indica) conforme metodologia proposta por Viana, Prates e Ribeiro (2006). Foi realizada irrigação complementar utilizando o método localizado por gotejamento, considerando as necessidades da cultura e com base na pluviosidade da região durante o período de condução do ensaio (Tabela 3).

Tabela 3. Médias das temperaturas máxima, mínima e média, precipitação e umidade relativa do ar em Ipanguaçu-RN, durante o período de janeiro/2012 a março/2012 Ipanguaçu - RN, IFRN, 2012.

\begin{tabular}{|c|c|c|c|c|c|}
\hline \multirow{2}{*}{ Meses de $2012^{1}$} & \multicolumn{3}{|c|}{ Temperatura $\left({ }^{\circ} \mathrm{C}\right)$} & \multirow{2}{*}{$\begin{array}{l}\text { Precipitação } \\
(\mathrm{mm})\end{array}$} & \multirow{2}{*}{$\begin{array}{l}\text { Umidade } \\
\text { Relativa (\%) }\end{array}$} \\
\hline & Máxima & Média & Mínima & & \\
\hline Janeiro & 30,04 & 28,36 & 26,31 & 31,4 & 66,37 \\
\hline Fevereiro & 30,16 & 27,70 & 23,40 & 97,4 & 70,40 \\
\hline Março & 29,45 & 28,18 & 26,00 & 60,2 & 69,76 \\
\hline Média & 29,88 & 28,08 & 25,24 & 63,00 & 68,84 \\
\hline
\end{tabular}

\footnotetext{
${ }^{1}$ Dados obtidos pela estação meteorológica do IFRN - Campus Ipanguaçu, Comunidade Base Física, Ipanguaçu-RN.
} 
As características avaliadas foram número e rendimento de espiguetas totais e comercializáveis, empalhadas e despalhadas, por hectare. Foram consideradas como espiguetas empalhadas comercializáveis aquelas livres de danos causados por pragas ou doenças e, como espiguetas despalhadas comercializáveis, aquelas com boa sanidade e que apresentavam cor variando de branco pérola a amarelo claro, formato cilíndrico, diâmetro variando de 0,8 a 1,8 cm e comprimento variando de 4 a $12 \mathrm{~cm}$. Foram feitas seis colheitas após o início da floração feminina, sendo a primeira realizada aos 54 dias após a semeadura, e as demais realizadas a cada dois dias. Os dados foram submetidos à análise de variância e teste de média utilizando o teste SNK a $5 \%$ de probabilidade e para a análise das densidades foi realizada análise de regressão, usando-se o software SISVAR versão 5.6 (Ferreira, 2011).

\section{RESULTADOS E DISCUSSÃO}

Houve efeito significativo dos tratamentos, pelo teste $\mathrm{F}$ da análise de variância a $1 \%$ de probabilidade, para número e rendimento de espiguetas totais e comercializáveis empalhadas, bem como para número e rendimento de espiguetas despalhadas comercializáveis.

Para número de espigas empalhadas, os valores obtidos nos tratamentos variaram de 78.951 a 129.971 espigas ha $^{-1}$, e de 75.474 a 128.331 para espigas comercializáveis ha ${ }^{-1}$. Os maiores valores foram observados no tratamento com duas plantas por cova com espaçamento de 0,15 m entre covas (T4), diferindo significativamente dos demais tratamentos. Para rendimento de espiguetas empalhadas, os valores totais variaram de 5,5 a 11,3 $\mathrm{t} \mathrm{ha}^{-1}$, e para espiguetas comercializáveis obteve-se valores variando de 5,3 a 11,1 $\mathrm{t} \mathrm{ha}^{-1}$. Os maiores rendimentos também foram observados no tratamento com $0,15 \mathrm{~m}$ entre covas e duas plantas por cova (T4), não diferindo do tratamento com 0,2 m entre covas com duas plantas por cova (T3) e sendo superior aos demais tratamentos (Tabela 4).

Tabela 4. Médias para número e rendimento de espiguetas de minimilho em função do espaçamento entre plantas e da densidade de plantas por cova. Ipanguaçu - RN, IFRN, 2012.

\begin{tabular}{ccccccc}
\hline \multirow{2}{*}{ Tratamentos } & \multicolumn{2}{c}{ Total empalhadas ha $^{-1}$} & \multicolumn{2}{c}{$\begin{array}{c}\text { Empalhadas comercializáveis } \\
\text { ha }^{-1}\end{array}$} & \multicolumn{2}{c}{$\begin{array}{c}\text { Despalhadas comercializáveis } \\
\text { ha }^{-1}\end{array}$} \\
\cline { 2 - 7 } & Número $^{1}$ & Rendimento (t) & Número & Rendimento (t) & Número & Rendimento (Kg) \\
\hline T1 & $78.951 \mathrm{~b}$ & $5,49 \mathrm{~b}$ & $75.474 \mathrm{~b}$ & $5,28 \mathrm{~b}$ & $59.832 \mathrm{c}$ & $597,3 \mathrm{~b}$ \\
T2 & $92.599 \mathrm{~b}$ & $6,28 \mathrm{~b}$ & $90.680 \mathrm{~b}$ & $5,97 \mathrm{~b}$ & $64.937 \mathrm{c}$ & $557,5 \mathrm{~b}$ \\
T3 & $129.971 \mathrm{~b}$ & $8,28 \mathrm{ab}$ & $128.331 \mathrm{~b}$ & $8,21 \mathrm{ab}$ & $100.977 \mathrm{~b}$ & $977,5 \mathrm{ab}$ \\
T4 & $190.625 \mathrm{a}$ & $11,32 \mathrm{a}$ & $183.211 \mathrm{a}$ & $11,09 \mathrm{a}$ & $136.386 \mathrm{a}$ & $1.240,0 \mathrm{a}$ \\
T5 & $99.070 \mathrm{~b}$ & $7,27 \mathrm{~b}$ & $98.376 \mathrm{~b}$ & $7,26 \mathrm{~b}$ & $71.341 \mathrm{bc}$ & $756,3 \mathrm{~b}$ \\
T6 & $88.993 \mathrm{~b}$ & $5,57 \mathrm{~b}$ & $88.993 \mathrm{~b}$ & $5,57 \mathrm{~b}$ & $70.025 \mathrm{bc}$ & $684,3 \mathrm{~b}$ \\
\hline CV (\%) & 23,66 & 27,94 & 22,21 & 26,76 & 20,96 & 29,06 \\
\hline
\end{tabular}

${ }^{1}$ Médias seguidas da mesma letra na coluna não diferem entre si pelo teste de SNK $(p<0,05)$

Com relação às espigas despalhadas, os maiores valores para número e rendimento foram observados no tratamento T4, no qual foram obtidas 136,4 mil espigas ha $^{-1}$ e rendimento de $1.240,0 \mathrm{Kg} \mathrm{ha}{ }^{-1}$, não diferindo do tratamento $\mathrm{T} 3 \mathrm{em}$ relação ao rendimento, diferindo 
significativamente dos demais. Este valor para rendimento foi superior ao observado por Santos et al. (2014) que avaliando a produção de minimilho na densidade de 15 plantas $\mathrm{m}^{-1}$ sob diferentes doses de adubação nitrogenada e potássica, em sistema convencional irrigado, obtiveram rendimentos variando de 800 a $1034 \mathrm{~kg} \mathrm{ha}^{-1}$. Os valores máximos para rendimento deste trabalho também foram superiores aos observados por Corrêa et al. (2014) que, em sistema orgânico sob adubação verde, obtiveram rendimento de espiguetas despalhadas de $797,2 \mathrm{~kg} \mathrm{ha}^{-1}$ para a densidade de 200.000 plantas ha ${ }^{-1}$.

Avaliando o efeito das densidades de 5,0; 7,0; 10,0 e 13,0 plantas por metro linear, referentes aos tratamentos T1, T2, T3 e T4, respectivamente, foi observado efeito significativo para as características testadas, sendo evidenciado efeito linear positivo em função do aumento da densidade. $O$ aumento na densidade de plantas por metro linear promoveu efeito linear positivo para número e rendimento de espiguetas empalhadas total (Figura 1) e comercializáveis (Figura 2), efeito também observado para espiguetas despalhadas comercializáveis (Figura 3), sendo os maiores valores observados quando se utilizou a densidade de 13 plantas $\mathrm{m}^{-1}$.

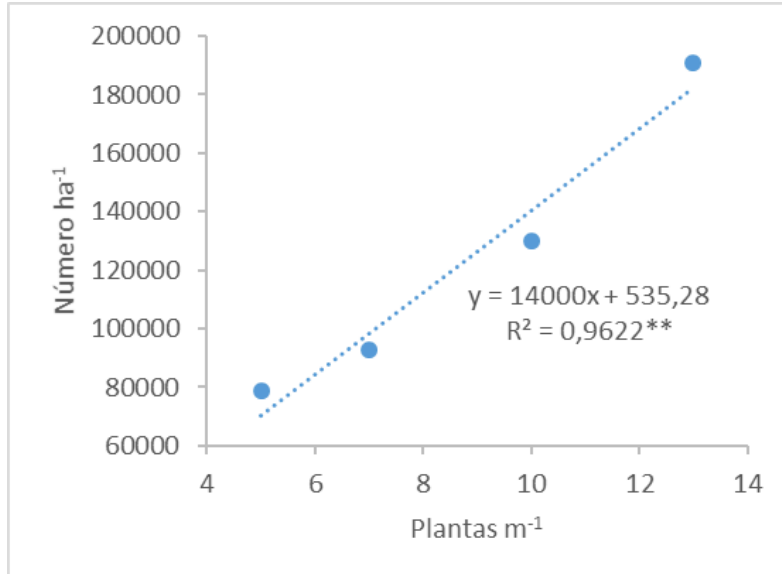

(A)

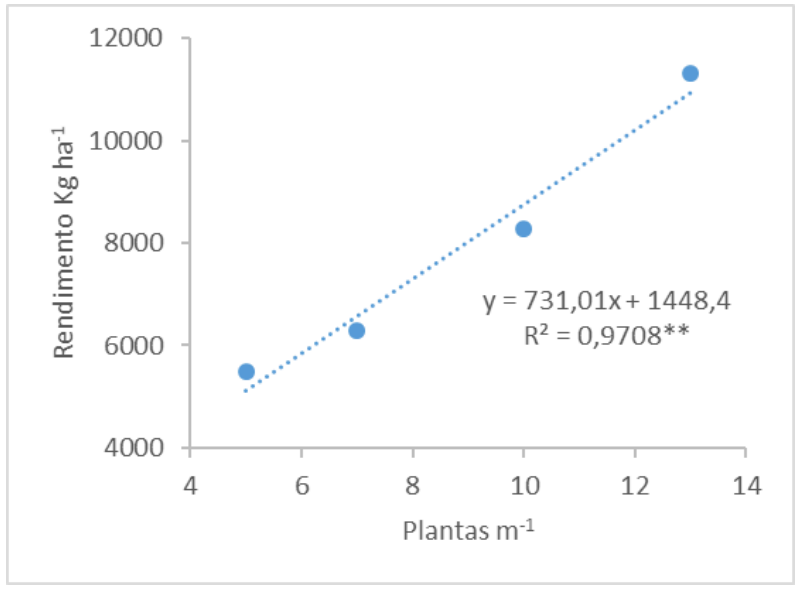

(B)

Figura 1. Número (A) e rendimento (B) total de espiguetas empalhadas em função da densidade de plantas $\mathrm{m}^{-1}$.

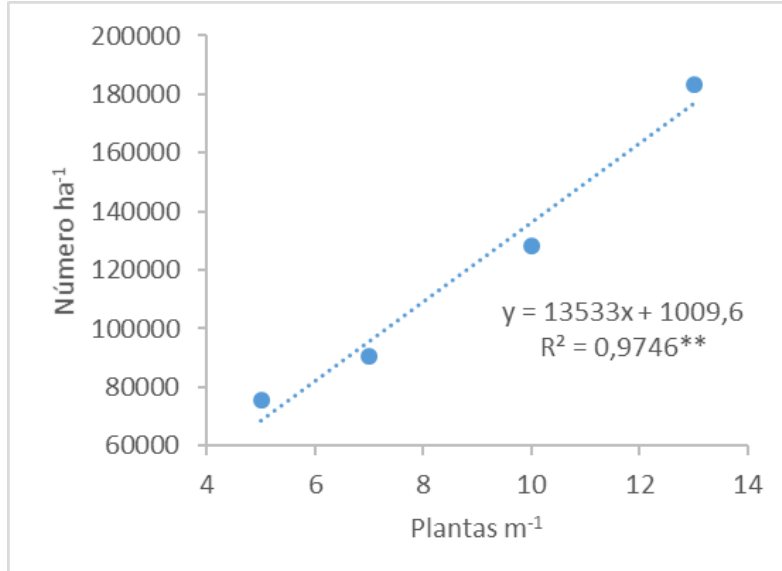

(A)

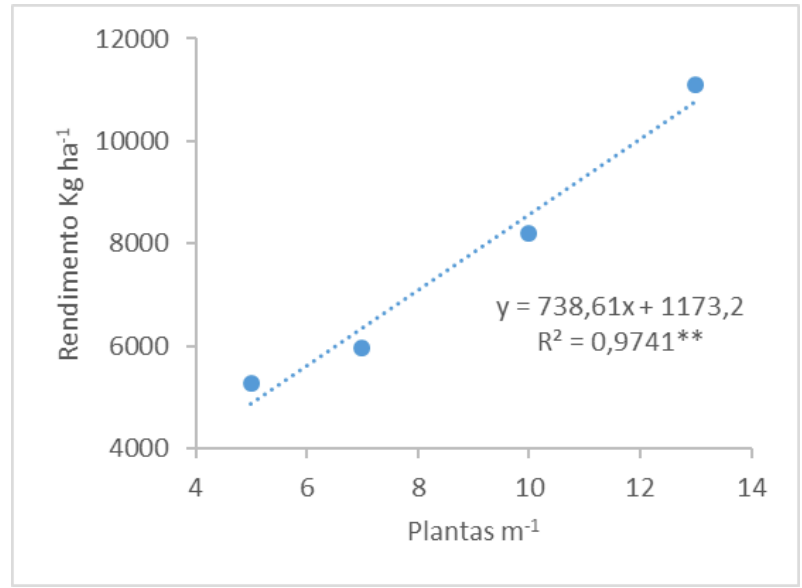

(B)

Figura 2. Número (A) e rendimento (B) de espiguetas empalhadas comercializáveis em função da densidade de plantas $\mathrm{m}^{-1}$. 




(A)

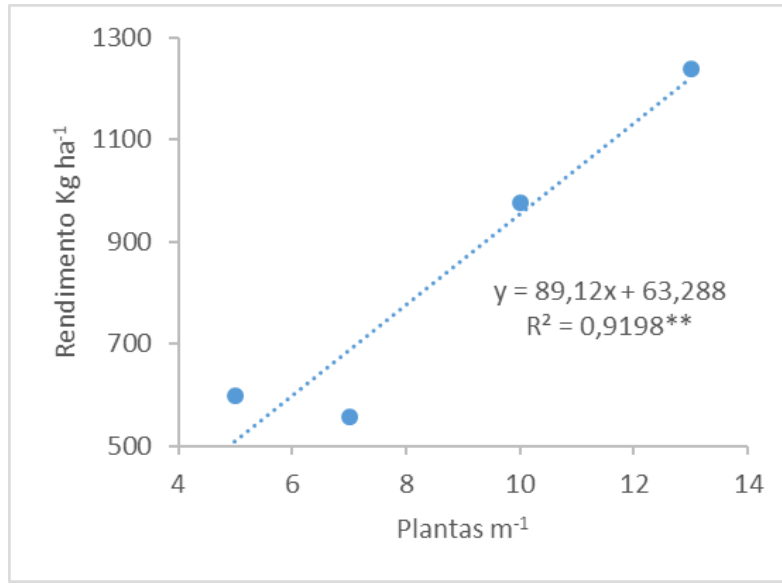

(B)

Figura 3. Número (A) e rendimento (B) de espiguetas despalhadas comercializáveis em função da densidade de plantas $\mathrm{m}^{-1}$.

Pereira Filho e Cruz (2002) também observaram o mesmo comportamento, onde o aumento da densidade promoveu incrementos na produção, e os melhores rendimentos foram obtidos quando cultivadas 15 plantas $\mathrm{m}^{-1}$. Os mesmos autores destacam que os espaçamentos entre linhas não devem ser muito fechados pois dificultaria a colheita, em virtude da mesma ser realizada de forma manual, e também o estreitamento do espaçamento entre linhas pode favorecer o aparecimento de pragas e doenças que podem comprometer a qualidade das espiguetas, fator de que deve ser levado em consideração para cultivos orgânicos.

Em ensaio conduzido por Wangen e Faria (2013) no estado de Minas Gerais testando diferentes variedades sob densidade de 14 plantas $\mathrm{m}^{-1}$, obtiveram rendimentos de espigas despalhadas com valores variando de 759,6 a $1.172,0 \mathrm{Kg} \mathrm{ha}{ }^{-1}$, valores semelhantes aos encontrados neste trabalho quando usadas as densidades 10 e 13 plantas $\mathrm{m}^{-1}$.

Em trabalhos realizados no Rio Grande do Norte utilizando a densidade de 50.000 plantas $\mathrm{ha}^{-1}$, que corresponde a 5,0 plantas $\mathrm{m}^{-1}$, Silva et al. (2006), utilizando cultivar híbrida, em sistema de cultivo convencional, obtiveram rendimentos comerciais de $831 \mathrm{~kg} \mathrm{ha}^{-1}$, porém em trabalho desenvolvido por Castro et al. (2013), testando diferentes materiais genéticos, obtiveram rendimentos variando de 426 a $500 \mathrm{Kg} \mathrm{ha}^{-1}$, valores inferiores aos observados neste trabalho.

\section{CONCLUSÃO}

O aumento da densidade de semeadura promoveu incrementos significativos no número e rendimento de espiguetas por hectare, sendo os maiores valores obtidos quando usada a densidade de 13 plantas $\mathrm{m}^{-1}$.

\section{REFERÊNCIAS}

Araújo JR, B. B., Silva, P. S. L., Morais, P. L. D., Dombroski, J. L. D. \& Oliveira, V. R. (2012). Crescimento do milho com controle de plantas daninhas via consorciação com gliricídia. Planta Daninha, 30(4), 767-774. 
Araújo Junior, B. B., Melo, A. E., Matias, J. N. R. \& Fontes, M. A. (2015). Avaliação de variedades crioulas de milho para produção orgânica no semiárido potiguar. Holos, 31(3), 102-108.

Castro, R. S., Silva, P. S. L. \& Cardoso, M. J. (2013). Baby corn, green corn, and dry corn yield of corn cultivars. Horticultura Brasileira, 31(1), 100-105.

Corrêa, A. L., Abboud, A. C. S., Guerra, J. G. M.; Aguiar, L. A. \& Ribeiro, R. L. D. (2014). Adubação verde com crotalária consorciada ao minimilho antecedendo a couve-folha sob manejo orgânico. Revista Ceres, 61(6), 956-963.

Costa, J. R. S. \& Silva, F. M. (2009, Julho). Análise da precipitação na cidade de Ipanguaçu/RN por imagens de satélite e distribuição de gumbel. Simpósio Brasileiro de Geografia Física Aplicada, Viçosa, MG, Brasil, 13.

Embrapa. (2006). Sistema brasileiro de classificação de solos. Brasília: EMBRAPA-SPI.

Ferreira, D. F. (2011). Sisvar: a computer statistical analysis system. Ciência e Agrotecnologia, 35(6), 1039-1042.

Melo, A. E., Araújo Junior, B. B., Figueiredo, J. P. M. \& Mendes, F. A. P. \& Pessoa, J. P. L. (2012, setembro). Produção de minimilho orgânico em função da densidade de plantio. Congresso Norte-Nordeste de Pesquisa e Inovação, Palmas, TO, Brasil, 7.

Moreira, J. N., Silva, P. S. L., Silva, K. M. B., Dombroski, J. L. D. \& Castro, R. S. (2010). Effect of detasseling on baby corn, green ear and grain yield of two maize hybrids. Horticultura Brasileira, 28(4), 406-411.

Pereira filho, I. A. \& Cruz, J. C. (2002). Manejo cultural de minimilho (Circular Técnica, 07). Sete Lagoas - MG: Embrapa Milho e Sorgo.

Santos, R. F., Inoue, T. T., Scapim, C. A., Clovis, L. R., Moterle, L. M. \& Saraiva, F. C. S. (2014). Produtividade de minimilho em função da adubação nitrogenada e potássica. Revista Ceres, 61(1), 121-129.

Silva, P. S. L., Araújo Junior, B. B., Oliveira, V. R., Pontes, F. S. T. \& Oliveira, O. F. (2013). Effects of nitrogen application on corn yield after harvesting the apical ear as baby corn. Horticultura Brasileira, 31(3), 419-425.

Silva, P. S. L., Silva, P. I. B., Sousa, A. K. F., Gurgel, K. M. \& Pereira Filho, I. A. (2006). Green ear yield and grain yield of maize after harvest of the first ear as baby corn. Horticultura Brasileira, 24(2), 151-155.

Viana, P. A., Prates, H. T. \& Ribeiro, P. E. A. (2006). Uso do extrato aquoso de nim para controle de Spodoptera frugiperda na cultura do milho (Circular Técnica, 88). Sete Lagoas-MG: Embrapa Milho e Sorgo.

Wangen, D. R. B. \& Faria, I. O. (2013). Avaliação de variedades de milho para produção de minimilho. Enciclopédia Biosfera, 9(17), 385-392. 